Taner Uluçay, Ahmet Ragıp Özpolat, İsa Yücel İşgör, Orhan Taşkesen Erzincan University, Erzincan-Turkey mlk_tan@windowslive.com; ahmetozpolat@hotmail.com yucelisgor@hotmail.com; orhantaskesen@gmail.com

http://dx.doi.org/10.12739/NWSA.2014.9.2.1C0616

\title{
LİSE ÖĞRENCİLERİNİN GELECEK BEKLENTİLERİ ÜZERİNE BİR ARAŞTIRMA ÖZET
}

Bu araştırmada, lise öğrencilerinin öğrenim gördükleri lise türlerine göre gelecek beklentilerinin belirlenmesi ve Güzel Sanatlar Liseleri ile diğer lise türlerine göre öğrencilerin gelecek beklentisi düzeylerinin karşılaştırılması amaçlanmıştır. Tarama araştırması niteliği taşıyan bu çalışma, yaşları 15-19 arasında değişen Ticaret, Anadolu, Öğretmen, Endüstri Meslek, Kız Meslek, Güzel sanatlar, Spor, Tarım, Sağlık, Turizm ve Otelcilik, İmam Hatip Liselerinin 1, 2., 3. ve 4 sınıflarından 926 öğrenci ile yürütülmüştür. Öğrencilerin gelecek beklentisi düzeyleri, FESA (Future Expectations Scale for Adolescents) ölçeğinin Türkçeye uyarlaması olan Ergen Gelecek Beklentileri Ölçeği ile ölçülmüştür. Okul türüne göre Aile ve Evlilik, Din ve Toplum, Sağlık ve Yaşam, İş ve Eğitim alt boyutunda gelecekten beklenti düzeylerini test etmek için Kruskal Wallis H testi, ortaya çıkan farkın hangi okul türleri arasında gerçekleştiğini test etmek için de Mann Whitney u testi kullanılmıştır. Okul türüne göre ergenlerin gelecek beklentileri arasında anlamlı fark bulunmuştur. Ergenlerin sıra ortalamaları dikkate alındığında, en yüksek gelecek beklentisine sahip okul türünün spor Lisesi(535.22), en düşük gelecek beklentisine ise GSSL (Müzik Böl.) (354.04 olduğu görülmektedir.

Anahtar Kelimeler: Lise, Gelecek Beklentisi, Ergen, Sanat Eğitimi, FESA

\section{A STUDY ON HIGH SCHOOL STUDENTS'FUTURE EXPECTATIONS ABSTRACT}

In this study, the aim is to determine high school students' future expectations according to high school type sand to research the difference in the hopelessness levels of students in high school fine arts and sports education departments in which art education is given and students in other high school types. This research is a descriptive one and it is conducted on 926 students whose ages vary between 15 and 19. Future expectations level of students is measured with scale Adolescents' Future Expectation which Turkish adaptation of the FESA (Future Expectations Scale for Adolescents). In analyzing the data, Kruskal Wallis $\mathrm{H}$ Test is used in order to test the future expectation level according to school type. While Mann Whitney U Test is used in order to test in which groups significant differences exist according to school type. There was a significant difference between adolescents' future expectation levels according to school type. Considering the mean rank of the adolescents in the study, higher levels of expectations related to future can be associated with high school of sports (535.22) and the lower levels of expectations related to future can be seen in High School of Fine Arts (Music department) (354.04).

Keywords: High School, Future Expectation, Adolescent, Art Education, FESA 


\section{GIRISS (INTRODUCTION)}

Modern yaşamın en önemli gerekliliklerinden birisi de bireyin geleceği ile ilgili planlama yapma zorunluluğudur. Gelecek tasarımı olarak da adlandırılan bu planlama, insanın kendine görev tayin etmesi anlamına gelir. Tayin edilen görevler kişinin gelecekten beklentisini oluştururken, aynı zamanda kişiden toplumun beklentisi algısı şeklinde de düşünülebilmektedir. Bu şekliyle beklenti kavramı, Türkçe Sözlük'te (Türk Dil Kurumu, 2011) bireysel anlamda "gerçekleşmesi beklenen şey" ya da "bireyin kendisinden beklenenler konusundaki öngörüsü" olarak tanımlanmaktadır.

"Ergenlik, kimlik bunalımlarıyla beraber gelecek planlamasının ortaya çıktığı bedensel, bilişsel, toplumsal ve ahlaki açıdan çeşitli değişikliklerin yaşandığı önemli bir gelişimsel görevdir." (Erikson, 1968). Sipma ve ark., (2012) göre ergenler arasında gelecek beklentilerinin ölçümü çoğunlukla tutarsızdır. McCabe ve Barnett (2000) gelecek beklentilerinin en yaygın olanının meslek çıktıları ve eğitim başarısı üzerine odaklanma eğilimi olduğunu ifade etmiştir. Bunun yanında "ergenlerin akademik beklentileri eğitim çıktılarının tahmini olarak gösterilmesi, eğitim farklılıklarını anlamada önemli bir faktör" (Turcios Cotto, Milan, 2013) olarak değerlendirilmektedir. Eğitim ve mesleki başarı beklentilerinin yanında iyi bir aile kurmak, sağlıklı bir yaşam sürdürmek ve inanca yönelik beklentilerde mevcuttur. Meslek seçimi ve başarı arasındaki fark, çoğu bilim ve sanat alanlarında görülmüştür (Mello, 2008:1070). Bütün bu çalışmalar dikkate alındığında beklentilerin cinsiyete, değerlere, kültüre, aile ve çevreye göre değişebilen unsurlar oldukları görülmektedir.

$\mathrm{Bu}$ dönemdeki değişimler, ergenler için uyum sorunlarını da beraberinde getirmektedir. Chardie ve ark. (2008:944) lise öğrencilerinin bu süreçte şimdiki kuşakların ulaştıklarından daha iyi eğitim ve daha iyi bir iş beklentisi içinde olduklarını ve birçoğunun da isteklerini nasıl gerçekleştireceklerinin farkında olmadıklarını ifade etmektedirler. Ergenlerin bu süreci sağlıklı bir şekilde geçirmeleri için, ruh sağlıklarını koruyucu özelliklerin belirlenip uygulamaya konulması önemlidir (Heubner, 1991). Gelecek tasarımının yapılmaya çalışıldığı bu dönemde; özellikle aile, çevre ve eğitim kurumlarına bazı görevler düşmektedir. Araştırmalar, genç ergenlerin ailelerinin üzerine odaklanırken, olgun ergenlerin daha çok kariyer üzerine odaklandığını ve kızların genellikle aileyi erkeklerden daha çok vurguladığını ortaya koymaktadır (Raffaelli ve Koller, 2005). Bu bulgulara göre ailenin bu sürece katkısının önemli olduğu açıktır. Ayrica gelecekle ilgili tutumlar birçok psikopatolojinin de gelişiminde önemli rol oynamaktadır. Bu tutumlardan birisi de umutsuzluktur (Dilbaz ve Seber, 1993, Çokluk, 2000). Tokuç ve ark. göre (2009) umut, kişinin gelecekteki hedeflere ulaşma olanaklarının olası yansıması; umutsuzluk ise, kişinin gelecekle ilgili olumsuz beklentileridir. Öğrencilerin gelecek öngörüsü, bireyin umutsuzluğunu pozitif yönde etkileyecek olan öznel iyi oluşuna olumlu katkılar sağlayacaktır. Elçin'e göre de (2000:296) insanları karşılaşacağı zorluklarla baş etmek ve gelişmeye yönelten kuvvet geleceğe beslediği umutlardır. Nitekim Eryılmaz'a göre (2011), lise öğrenimi gören ergenlerin olumlu gelecek beklentilerinin olması ile öznel iyi oluş düzeyleri arasında pozitif yönde anlamlı bir ilişki vardır. Diğer araştırmalara göre de (Kazakine, 1999; Guarino ve ark., 1999) gelecek zaman odaklı bireylerin, olumlu işlevsellikler sergiledikleri, sağlık kontrolü yaptırdıkları ve daha az psikopatoloji sergiledikleri görülmüşür. Fischhoff ve ark. (2000:189) gençlerin iyi bir iş umudu için, ev ödevi gibi hoşlanmadıkları şeyleri yapıp yapmayacaklarına karar vermek zorunda olduklarını belirtmişlerdir. Bu kararlar onların yaşamlarında oluşan belirsiz olayların olasılıklarının doğru 
değerlendirilmesini etkileyecektir. Gençlerin gelecekleri için bazı sorumlulukları yerine getirmeleri zorunluluktur. Fakat bazı araştırmalar da lise öğrencilerinin zorunlu olmadıkları aktivitelere katılımları ile gelecek beklentilerinin ilişkili olduğunu göstermiştir (Beal ve Crockett, 2010; Eccles ve Barber, 1999). Liselerde sürdürülen sosyal ve kültürel aktivitelerin beklenti düzeyleri üzerindeki etkisi dikkate alındığında, Güzel Sanatlar ve spor Lisesi gibi faaliyet ağırlıklı liselerin öğrencilerinin gelecek beklentilerinin ölçülmesi önemlidir. Lise öğrencilerinin beklenti düzeylerini ve beklenti düzeylerini etkileyen faktörlerin araştırıldığı çalışmalar mevcut olmasına rağmen (Başkonuş ve ark., 2011; Şimşek, 2011; Bayoğlu ve Purutçuoğlu, 2011; Tuncer, 2011; Yavuzer ve ark., 2005) hem lise türüne göre hem de sanat eğitimi alan Güzel sanatlar Lisesi öğrencilerinin gelecek beklentilerini araştıran bir çalışmaya rastlanmamıştır. Dolayısıyla, bu çalışmanın amacı, öncelikle lise öğrencilerinin öğrenim gördükleri lise türlerine göre gelecek beklentilerinin belirlenmesi ve Güzel Sanatlar Liselerinin sanat eğitimi alan bölümlerinin diğer lise türlerine göre gelecek beklentilerindeki farkın araştırılmasıdır.

Araştırma soruları:

- Öğrencilerin gelecek beklentisi ne düzeydedir?

- Öğrencilerin gelecek beklentileri okul türüne göre farklılık göstermekte midir?

\section{2. ÇALIŞMANIN ÖNEMI (RESEARCH SIGNIFICANCE)}

Öğrenciler, okul ortamına geleceğe ilişkin bazı beklentilerle gelirler. Öğrenciler öğrenim gördükleri okulun türüne göre farklı beklentilere sahiptirler. Öğrencilerin gelecekten beklentileri sadece eğitim ile sınırlı değildir. İyi bir aile kurma, inançlarını özgürce yaşama, iyi bir iş olanağı ve sağlıklı yaşam öğrencilerin diğer beklentileri arasındadır. Öğrencilerin beklenti düzeyleri geleceğe ilişkin umutları ile doğrudan ilişkilidir. Gelecek beklentisi düzeyi düşük olan öğrencinin umutsuzluk düzeyinin de düşük olduğu bilinmektedir. Öğrencilerin tamamının kendi tercihleri olan okullara gidemediği, çoğunluğun puanının yeterli geldiği lise türüne kayıt yaptırdığı düşünüldüğünde, bu öğrencilerin öğrenim gördükleri zaman içerisinde gelecek beklentilerinin ölçülmesi, onların öğrenim gördükleri okul ile ilgili önemli ipuçları verir. Öğrencilerin beklentilerinin ortalaması, okulun öğrencilere sağlayacağı özelde iş ve eğitim; genelde ise, aile, sağlık, inanç gibi beklentiler hakkında bilgiler sağlar. okul yöneticileri için yönetsel kararların alınmasında önemli bir göstergedir.

Özellikle ergenlikte gelecek planlamasının ergen için önemli bir sorun olduğu bilinmektedir. Bu dönemde, ergenin beklentilerinin yanında, aile ve toplumda ergenden beklentilerin ergen üzerinde bir baskı oluşturduğundan ergenin beklenti düzeylerinin ve boyutlarının belirlenmesi, ergene yardım ve rehberlikte kullanilabilir. Bu rehberlik, okullarda rehber öğretmenler, evlerde ise okulun bilgilendirmesi ile aileler tarafından yapılabilir.

Bu doğrultuda bu çalışma, farklı lise türlerinde öğrenim gören lise öğrencilerinin gelecek beklentilerini öğrenim gördükleri lise türlerine göre incelemektedir. Ayrıca bu çalışma ile sanat ve spor gibi aktivitelere sahip Güzel Sanatlar Lisesi ve spor Liselerinin gelecek beklentilerinin diğer lise türlerine göre farkı incelenmiş olacaktır. 


\section{YÖNTEM (METHOD)}

\subsection{Araştırma Modeli (Research Model)}

Lise öğrencilerinin öğrenim gördükleri okul türlerine göre gelecek beklentilerinin belirlendiği ve Güzel Sanatlar ve Spor Liselerinin sanat eğitimi alan bölümleri ile diğer lise türlerinin gelecek beklentileri bakımından karşılaştırıldığı bu çalışma, ilişkisel tarama modeline uygun bir çalışmadır.

\section{2. Çalışma Grubu (Study Group)}

Tarama araştırması niteliği taşıyan bu çalışma, Türkiye'nin Doğu Anadolu Bölgesinin orta ölçekli nüfusa sahip bir ilinde 2012-2013 eğitim öğretim yılında öğrenim gören 926 (464 kız, 451 erkek, 11 cinsiyeti belirtilmemiş) öğrenci ile yürütülmüştür. Çalışma grubunun yaş aralığı 15-19 olup yaş ortalaması 17'dir. Veriler, Ticaret, Anadolu, Öğretmen, Endüstri Meslek, Kız Meslek, Güzel sanatlar ve Spor, Tarım, Sağlık, Turizm ve Otelcilik, İmam Hatip Liselerinin 1., 2., 3. ve 4. sınıf öğrencilerinden toplanmıştır.

\subsection{Veri Toplama Araçları (Data Collection Tools)}

Bu araştırmada, öğrencilerin gelecek beklentileri düzeylerine ilişkin verilerin toplanması amacıyla McWhirter ve McWhirter (2008) tarafından geliştirilen FESA (Future Expectations Scale for Adolescents) ölçeğinin Tuncer (2011) tarafından Türkçeye uyarlaması olan Ergen Gelecek Beklentileri Ölçeği (EGBÖ) kullanılmıştır (Tuncer, 2011).

Orijinal ölçek 25 maddeden oluşmakta ve bütün maddeler "Yetişkin olduğumda" ile başlamaktadır. Ölçekteki en düşük puan 1, en yüksek puan 7"dir. Ölçek maddeleri "1: kesinlikle inanmıyorum" ve "7: kesinlikle inanıyorum" biçiminde puanlanmaktadır (Tuncer, 2011:1267). Öz değeri 1 alınan faktör analizi sonucunda ölçekteki faktör sayısı, İs ve Ĕ̆itim, Evlilik ve Aile, Din ve Toplum ve Sağlık ve Yaşam olmak üzere dört olarak bulunmuştur.

EGBÖ ölçeği açımlayıcı ve doğrulayıcı faktör analizleri sonuçlarına göre ölçeğin dört faktörlü yapısının uygun olduğuna karar verilmiştir. Ölçeğin birinci faktörü 11 maddeden, ikinci faktörü 7 maddeden, üçüncü faktörü 3 maddeden ve dördüncü faktörü 4 maddeden oluşmaktadır. Bu dört faktörlü yapının Cronbach Alfa katsayısı 0,925 bulunmuştur. Araştırmada ise, güvenirlik katsayısı, .87 olarak tespit edilmiştir.

\subsection{Verilerin Analizi (Data Analysis)}

Değişkenlere ilişkin betimsel istatistikler, varyans analizleri SPSS 17.00 programı kullanılarak $p<.05$ anlamlılık düzeyinde test edilmiştir. Öğrencilerin "Ergen Gelecek Beklentisi Ölçeği" puanları toplanarak gelecek beklentileri, alt boyutlara ilişkin puanları toplanarak alt boyuttaki Evlilik ve Aile, İş ve Eğitimi, Sağlık ve Yaşam, Din ve Toplum beklenti düzeyleri oluşturulmuştur. Verilerin analizinde, verilerin normal dağılım gösterip göstermediğini test etmek için, Kolmogorov Smirnov testi uygulanmış, verilerin normal dağılım göstermediği saptanmıştır. Verilerin normal dağılım göstermediği gerekçesiyle ergenlerin okul türüne göre gelecek beklentisi düzeylerini test etmek için Kruskal Wallis $\mathrm{H}$ test ve farkın hangi okul türlerinde gerçekleştiğini test etmek için ise Mann Whitney U testi kullanılmıştır. 
4. BULGULAR (FINDINGS)

4.1. Lise Öğrencilerinin Okul Türüne Göre Gelecek Beklentisi Toplam Puanları Arasındaki ve Alt Ölçek Puanları Arasındaki Farklara Ait Bulgular (Findings about the Difference at Future Expectation Level and Sub-Scales Cores of Highs School students according to School Types)

Lise öğrencilerinin devam ettikleri okul türlerine göre ergen gelecek beklentisi toplam puanları ile alt ölçek (aile ve evlilik, sağlık ve yaşam, iş ve eğitim, din ve toplum) puanlarının farklılaşıp farklılaşmadığını incelemek için Kruskalı Wallis testi yapılmış ve sonuçlar Tablo 1 verilmiştir.

Tablo 1. Lise öğrencilerinin gelecek beklentisi toplam puanlarının ve alt ölçek puanlarının devam ettikleri okul türüne göre kruskal-wallis testi sonuçları

(Tablo 1. Kruskall Wallis test results about differences between high schools tudents' future expectation total score sandsub-scale scores according to school types)

\begin{tabular}{|c|c|c|c|c|c|c|}
\hline Okul Türü & $\begin{array}{c}\text { Gelecek } \\
\text { Bekl. } \\
\text { Topl. } \\
\text { Sira } \\
\text { Ort. }\end{array}$ & $\begin{array}{c}\text { İş ve } \\
\text { Eğitim } \\
\text { Bekl. } \\
\text { Sıra } \\
\text { Ort. }\end{array}$ & $\begin{array}{c}\text { Evlilik } \\
\text { ve Aile } \\
\text { Bekl. } \\
\text { Sira } \\
\text { Ort. }\end{array}$ & $\begin{array}{c}\text { Din ve } \\
\text { Toplum } \\
\text { Bekl. } \\
\text { Sıra } \\
\text { Ort. }\end{array}$ & $\begin{array}{c}\text { Sağlık ve } \\
\text { Yaşam } \\
\text { Bekl. } \\
\text { Sıra Ort. }\end{array}$ & $\mathrm{N}$ \\
\hline Anadolu Lisesi & 462,55 & 517,57 & 430,78 & 369,73 & 462,89 & 97 \\
\hline Endüstri Mes. Lisesi & 470,92 & 425,81 & 492,28 & 524,04 & 421,72 & 104 \\
\hline GSSL (Resim Böl.) & 472,85 & 473,15 & 469,20 & 427,99 & 512,92 & 60 \\
\hline Kız Meslek Lisesi & 402,49 & 399,99 & 417,98 & 431,02 & 424,16 & 86 \\
\hline Tarım Lisesi & 483,44 & 480,80 & 472,70 & 494,86 & 442,56 & 97 \\
\hline Ticaret Lisesi & 534,03 & 554,47 & 516,62 & 478,40 & 541,59 & 97 \\
\hline Tur.ve Otelc. Lisesi & 455,77 & 440,47 & 484,77 & 435,08 & 509,69 & 75 \\
\hline İmam HatipLisesi & 477,23 & 427,17 & 505,09 & 602,03 & 411,49 & 73 \\
\hline Sağlık Meslek Lisesi & 460,43 & 475,29 & 444,77 & 452,47 & 420,60 & 82 \\
\hline GSSL (Spor Böl.) & 535,22 & 429,33 & 608,60 & 570,43 & 609,60 & 29 \\
\hline Öğretmen Lisesi & 432,79 & 461,70 & 410,36 & 446,03 & 488,57 & 86 \\
\hline GSSL (Müzik Böl.) & 354,04 & 403,85 & 337,88 & 327,53 & 381,91 & 40 \\
\hline Ki-Kare & 22,107 & 27,161 & 32,539 & 57,582 & 35,751 & \\
\hline $\mathrm{Sd}$ & 11 & 11 & 11 & 11 & 11 & \\
\hline $\mathrm{p}$ & .024 & .004 & .001 & .000 & .000 & \\
\hline
\end{tabular}

Tablo 1 incelendiğinde, öğrencilerin devam ettikleri okul türüne göre gelecek beklentisi toplam puanları ile ilgili ki-kare değerinin 22.107, iş ve eğitim alt boyutu ile ilgili ki-kare değerinin 27.161, evlilik ve aile alt boyutu ile ilgili ki-kare değerinin 32.539, din ve toplum alt boyutu ile ilgili ki-kare değerinin 57.582, sağlık ve yaşam alt boyutu ile ilgili ki-kare değerinin ise 35.751 olduğu ve bu değerlerin $\mathrm{p}<.05$ düzeyinde anlamlı olduğu görülmektedir. Analiz sonucunda elde edilen bu anlamlı farkın hangi gruplar arasında olduğunu belirlemek amacıyla Mann Whitney U testi yapılmış ve sonuçlar ilgili tablolarda verilmiştir.

\subsubsection{Lise Öğrencilerinin Okul Türüne Göre Gelecek Beklentisi Toplam Puanları Arasındaki Farka Ait Bulgular (Findings about the Difference at Future Expectation Total Scores of Highs School Students according to School Types)}

Tablo 2 incelendiğinde, öğrencilerin devam ettikleri okul türüne göre gelecek beklentisi toplam puanları ile ilgili ki-kare değerinin 22.107 olduğu ve bu değerlerin $\mathrm{p}<.05$ düzeyinde anlamlı olduğu görülmektedir. Analiz sonucunda elde edilen bu anlamlı farkın hangi 
gruplar arasında olduğunu belirlemek amacıyla Mann Whitney u testi yapılmış ve sonuçlar Tablo 2'de verilmiştir.

Tablo 2 incelendiğinde anlamlı farkın hangi gruplar arasında olduğunu belirlemek amacıyla yapılan Mann Whitney U testi ikili karşılaştırmalarında tüm lise türleri arasındaki farkın anlamlı olduğu görülmüştür. Tabloda ikili karşılaştırmalar arasındaki bu anlamlı farkın hangi okulun lehine olduğu ( U değeri ve sıra ortalamasına bakılarak) koyu karakterle belirtilmiştir.

Tablo 2. Gelecek beklentisi toplam puanları arasındaki farkın kaynağını belirlemeye yönelik Mann Whitney U testi sonuçları

(Tablo 2. MANN-WHITNEY U test results about the difference in high school students' future expectation total scores according to school

\begin{tabular}{|c|c|c|c|c|c|}
\hline Lise Türü & $\mathrm{N}$ & $\begin{array}{c}\text { types) } \\
\text { Sıra } \\
\text { Ortalaması }\end{array}$ & $\begin{array}{c}\text { Sıra } \\
\text { Toplamı }\end{array}$ & $\mathrm{U}$ & $\mathrm{p}$ \\
\hline Erkek Mes. Lis. & 104 & 77,59 & 8069,5 & \multirow{2}{*}{1550,5} & \multirow{2}{*}{.018} \\
\hline GSSL (Müzik) & 40 & 59,26 & 2370,5 & & \\
\hline GSSI (Resim) & 60 & 56,29 & 3377,5 & \multirow{2}{*}{852,5} & \multirow{2}{*}{.014} \\
\hline GSSL (Müzik) & 40 & 41,81 & 1672,5 & & \\
\hline Kız Mes. Lis. & 86 & 83,44 & 7175,5 & \multirow{2}{*}{3434,5} & \multirow{2}{*}{.039} \\
\hline Tarım Mes. Lis. & 97 & 99,59 & 9660,5 & & \\
\hline Kız Mes. Lis. & 86 & 79,29 & 6819 & \multirow{2}{*}{3078} & \multirow{2}{*}{.002} \\
\hline Ticaret Lisesi & 97 & 103,27 & 10017 & & \\
\hline Kız Mes. Lis. & 86 & 53,71 & 4619 & \multirow{2}{*}{878} & \multirow{2}{*}{.017} \\
\hline Spor Lisesi & 29 & 70,72 & 2051 & & \\
\hline Tarım Mes. Lis. & 97 & 74,55 & 7231,5 & \multirow{2}{*}{1401,5} & \multirow{2}{*}{.011} \\
\hline GSSL (Müzik) & 40 & 55,54 & 2221,5 & & \\
\hline Ticaret Lisesi & 97 & 97,32 & 9440,5 & \multirow{2}{*}{3266,5} & \multirow{2}{*}{.04} \\
\hline Sağlık Mes. Lis. & 82 & 81,34 & 6669,5 & & \\
\hline Ticaret Lisesi & 97 & 101,1 & 9807 & \multirow{2}{*}{3288} & \multirow{2}{*}{.014} \\
\hline Öğretmen Lisesi & 86 & 81,73 & 7029 & & \\
\hline Ticaret Lisesi & 97 & 76,31 & 7402,5 & \multirow{2}{*}{1230,5} & \multirow{2}{*}{.001} \\
\hline GSSL (Müzik) & 40 & 51,26 & 2050,5 & & \\
\hline İmam Hat. Lisesi & 73 & 62,78 & 4583 & \multirow{2}{*}{1038} & \multirow{2}{*}{.011} \\
\hline GSSL (Müzik) & 40 & 46,45 & 1858 & & \\
\hline Sağlık Mes. Lis. & 82 & 66,85 & 5481,5 & \multirow{2}{*}{1201,5} & \multirow{2}{*}{.017} \\
\hline GSSL (Müzik) & 40 & 50,54 & 2021,5 & & \\
\hline Spor Lisesi & 29 & 43,52 & 1262 & \multirow{2}{*}{333} & \multirow{2}{*}{.003} \\
\hline GSSL (Müzik) & 40 & 28,83 & 1153 & & \\
\hline
\end{tabular}

4.1.2. Lise Öğrencilerinin Okul Türüne Göre İş ve Eğitim Alt Ölçek Puanı Arasındaki Farka Ait Bulgular (Findings about the Difference at Workand Education Sub-Scalescores of High School students according to School Types)

Okul türüne göre iş ve eğitim alt boyutunda elde edilen anlamlı farkın hangi gruplar arasında olduğunu belirlemek amacıyla Mann Whitney U testi yapılmış ve sonuçlar Tablo 3'de verilmiştir.

Tablo 3 incelendiğinde anlamlı farkın hangi gruplar arasında olduğunu belirlemek amacıyla yapılan Mann Whitney U testi ikili karşılaştırmalarında tüm lise türleri arasındaki farkın anlamlı olduğu görülmüştür. Tabloda ikili karşılaştırmalar arasındaki bu anlamlı farkın hangi okulun lehine olduğu (U değeri ve sıra ortalamasına bakılarak) koyu karakterle belirtilmiştir. 
Tablo 3. İş ve Eğitim Alt Ölçek Puanı Arasındaki Farkın Kaynağını Belirlemeye Yönelik Mann Whitney U Testi Sonuçları

(Tablo 3. MANN-WHITNEY U Test results about the difference in high school students' sub-scale (Workand education)scores according to school types)

\begin{tabular}{|c|c|c|c|c|c|}
\hline Lise Türü & $\mathrm{N}$ & $\begin{array}{c}\text { Sira } \\
\text { Ortalaması }\end{array}$ & $\begin{array}{c}\text { Sira } \\
\text { Toplamı }\end{array}$ & $\mathrm{U}$ & $\mathrm{p}$ \\
\hline Erzincan Lisesi & 97 & 111,34 & 10800 & \multirow{2}{*}{4041} & \multirow{2}{*}{0,015} \\
\hline Erkek Mes. Lis. & 104 & 91,36 & 9501 & & \\
\hline Erzincan Lisesi & 97 & 102,04 & 9898 & \multirow{2}{*}{3197} & \multirow{2}{*}{0,006} \\
\hline Kız Mes. Lis. & 86 & 80,67 & 6938 & & \\
\hline Erzincan Lisesi & 97 & 73,95 & 7173 & \multirow{2}{*}{1460} & \multirow{2}{*}{0,023} \\
\hline GSSL (Müzik) & 40 & 57 & 2280 & & \\
\hline Erkek Mes. Lis. & 104 & 87,92 & 9144 & \multirow{2}{*}{3684} & \multirow{2}{*}{0,001} \\
\hline Ticaret Lisesi & 97 & 115,02 & 11157 & & \\
\hline GSSL (Resim) & 60 & 69,95 & 4197 & \multirow{2}{*}{2367} & \multirow{2}{*}{0,049} \\
\hline Ticaret Lisesi & 97 & 84,6 & 8206 & & \\
\hline Kız Mes. Lis. & 86 & 83,44 & 7175,5 & \multirow{2}{*}{3434,5} & \multirow{2}{*}{0,039} \\
\hline TarımkMes. Lis. & 97 & 99,59 & 9660,5 & & \\
\hline Kız Mes. Lis. & 86 & 77,71 & 6683 & \multirow{2}{*}{2942} & \multirow{2}{*}{0,001} \\
\hline Ticaret Lisesi & 97 & 104,67 & 10153 & & \\
\hline Kız Mes. Lis. & 86 & 77,22 & 6640,5 & \multirow{2}{*}{2899,5} & \multirow{2}{*}{0,047} \\
\hline Sağlık Mes. Lis. & 82 & 92,14 & 7555,5 & & \\
\hline Tarım Mes. Lis. & 97 & 88,7 & 8603,5 & \multirow{2}{*}{3850,5} & \multirow{2}{*}{0,029} \\
\hline Ticaret Lisesi & 97 & 106,3 & 10311,5 & & \\
\hline Ticaret Lisesi & 97 & 95,49 & 9263 & \multirow{2}{*}{2765} & \multirow{2}{*}{0,007} \\
\hline Turizm Mes. Lis. & 75 & 74,87 & 5615 & & \\
\hline Ticaret Lisesi & 97 & 95,44 & 9257,5 & \multirow{2}{*}{2576,5} & \multirow{2}{*}{0,002} \\
\hline İmam Hat. Lis. & 73 & 72,29 & 5277,5 & & \\
\hline Ticaret Lisesi & 97 & 97,72 & 9479 & \multirow{2}{*}{3228} & \multirow{2}{*}{0,03} \\
\hline Sağlık Mes. Lis. & 82 & 80,87 & 6631 & & \\
\hline Ticaret Lisesi & 97 & 67,24 & 6522 & \multirow{2}{*}{1044} & \multirow{2}{*}{0,035} \\
\hline Spor Lisesi & 29 & 51 & 1479 & & \\
\hline Ticaret Lisesi & 97 & 100,72 & 9769,5 & \multirow{2}{*}{3325,5} & \multirow{2}{*}{0,018} \\
\hline Öğretmen Lisesi & 86 & 82,17 & 7066,5 & & \\
\hline Ticaret Lisesi & 97 & 75,32 & 7306 & \multirow{2}{*}{1327} & \multirow{2}{*}{0,004} \\
\hline GSSL (Müzik) & 40 & 53,68 & 2147 & & \\
\hline
\end{tabular}

\subsubsection{Lise Öğrencilerinin Okul Türüne Türüne Göre Evlilik ve Aile Alt Ölçek Puanı Arasındaki Farka Ait Bulgular (Findings about the Difference at Sub-Scale (Mariage and Family) Scores of High School students according to School Types)}

Evlilik ve aile alt boyutu ile ilgili ki-kare değerinin 32.539 olduğu ve bu değerin p<.05 düzeyinde anlamlı olduğu görülmektedir. Bu anlamlı farkın hangi gruplar arasında olduğunu belirlemek amacıyla Mann Whitney U testi yapılmış ve sonuçlar Tablo 4'de verilmiştir.

Tablo 4'de tüm lise türleri arasındaki farkın anlamlı olduğu görülmüştür. Tabloda ikili karşılaştırmalar arasındaki bu anlamlı farkın hangi okulun lehine olduğu ( U değeri ve sıra ortalamasına bakılarak) koyu karakterle belirtilmiştir. 
Tablo 4. Evlilik ve aile alt ölçek puanı arasındaki farkın kaynağını belirlemeye yönelik Mann Whitney U testi sonuçları

(Tablo 4. MANN-WHITNEY U test results about the difference in high school students' sub-scale (mariage and family) scores according to school types)

\begin{tabular}{|c|c|c|c|c|c|}
\hline Lise Türü & $\mathrm{N}$ & Sıra Ortalaması & Sıra Toplamı & U & $\mathrm{p}$ \\
\hline Erzincan Lisesi & 97 & 89,4 & 8671,5 & \multirow{2}{*}{3918,5} & \multirow{2}{*}{.044} \\
\hline Ticaret Lisesi & 97 & 105,6 & 10243,5 & & \\
\hline Erzincan Lisesi & 97 & 58,68 & 5691,5 & \multirow{2}{*}{938,5} & \multirow{2}{*}{.007} \\
\hline Spor Lisesi & 29 & 79,64 & 2309,5 & & \\
\hline Erkek Mes. Lis. & 104 & 63,36 & 6589 & \multirow{2}{*}{1129} & \multirow{2}{*}{.039} \\
\hline Spor Lisesi & 29 & 80,07 & 2322 & & \\
\hline Erkek Mes. Lis. & 104 & 103,34 & 10747 & \multirow{2}{*}{3657} & \multirow{2}{*}{.031} \\
\hline Öğretmen Lisesi & 86 & 86,02 & 7398 & & \\
\hline Erkek Mes. Lis. & 104 & 79,12 & 8228,5 & \multirow{2}{*}{1391,5} & \multirow{2}{*}{.002} \\
\hline GSSL (Müzik) & 40 & 55,29 & 2211,5 & & \\
\hline GSSL (Resim) & 60 & 40,13 & 2407,5 & \multirow{2}{*}{577,5} & \multirow{2}{*}{.01} \\
\hline Spor Lisesi & 29 & 55,09 & 1597,5 & & \\
\hline GSSL (Resim) & 60 & 56,83 & 3409,5 & \multirow{2}{*}{820,5} & \multirow{2}{*}{.008} \\
\hline GSSL (Müzik) & 40 & 41,01 & 1640,5 & & \\
\hline Kız Mes. Lisesi & 86 & 81,83 & 7037 & \multirow{2}{*}{3296} & \multirow{2}{*}{.014} \\
\hline Ticaret Lisesi & 97 & 101,02 & 9799 & & \\
\hline Kız Mes. Lisesi & 86 & 72,47 & 6232,5 & \multirow{2}{*}{2491,5} & \multirow{2}{*}{.025} \\
\hline İmam Hat. Lisesi & 73 & 88,87 & 6487,5 & & \\
\hline Kız Mes. Lisesi & 86 & 51,85 & 4459 & \multirow{2}{*}{718} & \multirow{2}{*}{.001} \\
\hline Spor Lisesi & 29 & 76,24 & 2211 & & \\
\hline Tarım Mes.Lisesi & 97 & 59,28 & 5750,5 & \multirow{2}{*}{997,5} & \multirow{2}{*}{.018} \\
\hline Spor Lisesi & 29 & 77,6 & 2250,5 & & \\
\hline Tarım Mes. Lis. & 97 & 74,76 & 7251,5 & & 008 \\
\hline GSSL (Müzik) & 40 & 55,04 & 2201,5 & 1381,5 & .008 \\
\hline Ticaret Lisesi & 97 & 92,35 & 8958 & 3331 & 061 \\
\hline Sağ. Mes. Lisesi & 82 & 87,22 & 7152 & 3331 & .061 \\
\hline Ticaret Lisesi & 97 & 101,62 & 9857 & 3238 & 009 \\
\hline Öğretm. Lisesi & 86 & 81,15 & 6979 & 3238 & .005 \\
\hline Ticaret Lisesi & 97 & 76,43 & 7414 & 1219 & 001 \\
\hline GSSL (Müzik) & 40 & 50,98 & 2039 & $12 \perp y$ & .001 \\
\hline Turizm Mes. Lis. & 75 & 48,87 & 3665,5 & 8155 & 048 \\
\hline Spor Lisesi & 29 & 61,88 & 1794,5 & $8 \perp 5,5$ & .048 \\
\hline Turizm Mes. Lis. & 75 & 63,8 & 4785 & 1065 & 011 \\
\hline GSSL (Müzik) & 40 & 47,13 & 1885 & 1065 & \\
\hline İmam Hat. Lisesi & 73 & 47,81 & 3490 & 789 & 045 \\
\hline Spor Lisesi & 29 & 60,79 & 1763 & 189 & \\
\hline İmam Hat. Lisesi & 73 & 89,45 & 6529,5 & 24495 & 017 \\
\hline Öğretm. Lisesi & 86 & 71,98 & 6190,5 & 2449,5 & \\
\hline İmam Hat. Lis. & 73 & 64,6 & 4716 & 905 & 001 \\
\hline GSSL (Müzik) & 40 & 43,13 & 1725 & 905 & .001 \\
\hline Sağlık Mes. Lisesi & 82 & 50,43 & 4135 & 732 & ?ח0 \\
\hline Spor Lisesi & 29 & 71,76 & 2081 & 132 & .002 \\
\hline Sağlık Mes. Lis. & 82 & 66,7 & 5469 & 1214 & 02 \\
\hline GSSL (Müzik) & 40 & 50,85 & 2034 & & .02 \\
\hline Spor Lisesi & 29 & 77,21 & 2239 & 690 & 000 \\
\hline Öğretmen Lisesi & 86 & 51,52 & 4431 & & \\
\hline Spor Lisesi & 29 & 46,5 & 1348,5 & 246.5 & 000 \\
\hline GSSL (Müzik) & 40 & 26,66 & 1066,5 & 240,5 & \\
\hline
\end{tabular}

\subsubsection{Lise Öğrencilerinin Okul Türüne Göre Din ve Toplum Alt} Ölçek Puanı Arasındaki Farka Ait Bulgular (Findings about the Difference at Sub-Scale (Religion and Society) Scores of High School students according to School Types)

Okul türüne göre din ve toplum alt boyutu ile ilgili anlamlı farkın hangi gruplar arasında olduğunu belirlemek amacıyla Mann Whitney U testi yapılmış ve sonuçlar Tablo 5'de verilmiştir.

Tablo 5'de tüm lise türleri arasındaki farkın anlamlı olduğu görülmüştür. Tabloda ikili karşılaştırmalar arasındaki bu anlamlı farkın hangi okulun lehine olduğu (U değeri ve sıra ortalamasına bakılarak) koyu karakterle belirtilmiştir. 
Tablo 5. Din ve toplum alt ölçek puanı arasındaki farkın kaynağını belirlemeye yönelik Mann Whitney U testi sonuçları

Tablo 5. (MANN-WHITNEY U test results about the difference in high

school students' sub-scale (religion and society) scores according to

\begin{tabular}{|c|c|c|c|c|c|}
\hline Lise Türü & $\mathrm{N}$ & Sıra Ortalaması & Sıra Toplamı & U & $\mathrm{p}$ \\
\hline Erzincan Lisesi & 97 & 83,39 & 8088,5 & \multirow{2}{*}{3335,5} & \multirow{2}{*}{.000} \\
\hline Erkek Mes. Lis. & 104 & 117,43 & 12212,5 & & \\
\hline Erzincan Lisesi & 97 & 84,8 & 8225,5 & \multirow{2}{*}{3472,5} & \multirow{2}{*}{.002} \\
\hline Tarım Mes. Lis. & 97 & 110,2 & 10689,5 & & \\
\hline Erzincan Lisesi & 97 & 87,24 & 8462 & \multirow{2}{*}{3709} & \multirow{2}{*}{.011} \\
\hline Ticaret Lisesi & 97 & 107,76 & 10453 & & \\
\hline Erzincan Lisesi & 97 & 68,03 & 6599 & \multirow{2}{*}{1846} & \multirow{2}{*}{.000} \\
\hline İmam Hat. Lisesi & 73 & 108,71 & 7936 & & \\
\hline Erzincan Lisesi & 97 & 82,05 & 7958,5 & \multirow{2}{*}{3205,5} & \multirow{2}{*}{.025} \\
\hline Sağlık Mes. Lis. & 82 & 99,41 & 8151,5 & & \\
\hline Erzincan Lisesi & 97 & 57,64 & 5591,5 & \multirow{2}{*}{838,5} & \multirow{2}{*}{.001} \\
\hline Spor Lisesi & 29 & 83,09 & 2409,5 & & \\
\hline Erzincan Lisesi & 97 & 83,87 & 8135 & \multirow{2}{*}{3382} & \\
\hline Öğretmen Lisesi & 86 & 101,17 & 8701 & & .027 \\
\hline Erkek Mes. Lis. & 104 & 89,45 & 9302,5 & & 013 \\
\hline GSSL (Resim) & 60 & 70,46 & 4227,5 & 2397,5 & .013 \\
\hline Erkek Mes. Lis. & 104 & 104,3 & 10847,5 & 35565 & 015 \\
\hline Kız Mes. Lis. & 86 & 84,85 & 7297,5 & 3556,5 & .010 \\
\hline Erkek Mes. Lis. & 104 & 97,04 & 10092,5 & & \\
\hline Turizm Mes. Lis. & 75 & 80,23 & 6017,5 & 3167,5 & .031 \\
\hline Erkek Mes. Lis. & 104 & 81,99 & 8527 & & \\
\hline İmam Hat. Lisesi & 73 & 98,99 & 7226 & 3067 & .029 \\
\hline Erkek Mes. Lis. & 104 & 103,55 & 10769,5 & & \\
\hline Öğretmen Lisesi & 86 & 85,76 & 7375,5 & 3634,5 & .026 \\
\hline Erkek Mes. Lis. & 104 & 81,21 & 8446 & & 000 \\
\hline GSSL (Müzik) & 40 & 49,85 & 1994 & $11 / 4$ & .000 \\
\hline GSSL (Resim) & 60 & 52,35 & 3141 & & \\
\hline İmam Hat. Lisesi & 73 & 79,04 & 5770 & 1311 & .000 \\
\hline GSSL (Resim) & 60 & 40,13 & 2407,5 & & \\
\hline Spor Lisesi & 29 & 55,09 & 1597,5 & 577,5 & .01 \\
\hline GSSL (Resim) & 60 & 55,64 & 3338,5 & 8915 & 029 \\
\hline GSSL (Müzik) & 40 & 42,79 & 1711,5 & 891,5 & .029 \\
\hline Kız Mes. Lis. & 86 & 66,35 & 5706 & & \\
\hline İmam Hat. Lisesi & 73 & 96,08 & 7014 & 1965 & .000 \\
\hline Kız Mes. Lis. & 86 & 53,51 & 4602 & & 012 \\
\hline Spor Lisesi & 29 & 71,31 & 2068 & 861 & .012 \\
\hline Kız Mes. Lis. & 86 & 68,17 & 5862,5 & & 035 \\
\hline GSSL (Müzik) & 40 & 53,46 & 2138,5 & 1318,5 & .035 \\
\hline Tarım Mes. Lis. & 97 & 77,15 & 7484 & & \\
\hline İmam Hat. Lisesi & 73 & 96,59 & 7051 & 2731 & .01 \\
\hline Tarım Mes. Lis. & 97 & 76,03 & 7374,5 & & 001 \\
\hline GSSL (Müzik) & 40 & 51,96 & 2078,5 & 1258,5 & .001 \\
\hline Ticaret Lisesi & 97 & 76,96 & 7465 & & \\
\hline İmam Hat. Lisesi & 73 & 96,85 & 7070 & 2712 & .009 \\
\hline Ticaret Lisesi & 97 & 74,91 & 7266,5 & & \\
\hline GSSL (Müzik) & 40 & 54,66 & 2186,5 & 1366,5 & .006 \\
\hline Turizm Mes. Lis. & 75 & 62,21 & 4666 & & \\
\hline İmam Hat. Lisesi & 73 & 87,12 & 6360 & 1816 & .000 \\
\hline Turizm Mes. Lis. & 75 & 48,68 & 3651 & & \\
\hline Spor Lisesi & 29 & 62,38 & 1809 & 801 & .037 \\
\hline İmam Hat. Lisesi & 73 & 92,43 & 6747,5 & & \\
\hline Sağlık Mes. Lis. & 82 & 65,15 & 5342,5 & 1939,5 & .000 \\
\hline İmam Hat. Lisesi & 73 & 95,43 & 6966,5 & & קח חמת \\
\hline Öğretmen Lisesi & 86 & 66,9 & 5753,5 & 2012,5 & .000 \\
\hline İmam Hat. Lisesi & 73 & 68,38 & 4992 & & \\
\hline GSSL (Müzik) & 40 & 36,23 & 1449 & 629 & .000 \\
\hline Sağlık Mes. Lis. & 82 & 52,06 & 4269 & & \\
\hline Spor Lisesi & 29 & 67,14 & 1947 & 866 & .029 \\
\hline Sağlık Mes. Lis. & 82 & 67,48 & 5533 & 1150 & 007 \\
\hline GSSL (Müzik) & 40 & 49,25 & 1970 & 1150 & .007 \\
\hline Spor Lisesi & 29 & 70,95 & 2057,5 & & \\
\hline Öğretmen Lisesi & 86 & 53,63 & 4612,5 & 871,5 & .015 \\
\hline Spor Lisesi & 29 & 44,78 & 1298,5 & & \\
\hline GSSL (Müzik) & 40 & 27,91 & 1116,5 & 296,5 & .001 \\
\hline Öğretmen Lisesi & 86 & 69,18 & 5949,5 & & \\
\hline GSSL (Müzik) & 40 & 51,29 & 2051,5 & 1231,5 & .01 \\
\hline
\end{tabular}




\subsubsection{Lise Öğrencilerinin Okul Türüne Göre Sağlık ve Yaşam Alt Ölçek Puanı Arasındaki Farka Ait Bulgular (Findings about the Difference at Sub-Scale (Healty and Life) Scores of High School Students according to School Types)}

Tablo 1 incelendiğinde öğrencilerin devam ettikleri okul türüne göre sağlık ve yaşam alt boyutu ile ilgili ki-kare değerinin 35.751 olduğu ve bu değerin $\mathrm{p}<.05$ düzeyinde anlamlı olduğu görülmektedir. Analiz sonucunda elde edilen bu anlamlı farkın hangi gruplar arasında olduğunu belirlemek amacıyla Mann Whitney U testi yapılmış ve sonuçlar Tablo 6'da verilmiştir.

Tablo 6. Sağlık ve yaşam alt ölçek puanı arasındaki farkın kaynağını belirlemeye yönelik Mann Whitney U testi sonuçları

(Tablo 6. MANN-WHITNEY U test results about the difference in high school students' sub-scale (religion and society) scores according to school types)

\begin{tabular}{|c|c|c|c|c|c|}
\hline Lise Türü & $\mathrm{N}$ & Sira Ortalaması & Sıra Toplamı & $\mathrm{U}$ & $\mathrm{p}$ \\
\hline Erzincan Lisesi & 97 & 89,92 & 8722,5 & \multirow{2}{*}{3969,5} & \multirow{2}{*}{.06} \\
\hline Ticaret Lisesi & 97 & 105,08 & 10192,5 & & \\
\hline Erzincan Lisesi & 97 & 59,39 & 5761 & \multirow{2}{*}{1008} & \multirow{2}{*}{.021} \\
\hline Spor Lisesi & 29 & 77,24 & 2240 & & \\
\hline Erkek Mes. Lis. & 104 & 89,77 & 9336 & \multirow{2}{*}{3876} & \multirow{2}{*}{.004} \\
\hline Ticaret Lisesi & 97 & 113,04 & 10965 & & \\
\hline Erkek Mes. Lis & 104 & 83,15 & 8647,5 & \multirow[b]{2}{*}{3187,5} & \multirow{2}{*}{.037} \\
\hline Turizm Mes. Lis. & 75 & 99,5 & 7462,5 & & \\
\hline Erkek Mes. Lis. & 104 & 61,32 & 6377,5 & \multirow{2}{*}{917,5} & \multirow{2}{*}{.001} \\
\hline Spor Lisesi & 29 & 87,36 & 2533,5 & & \\
\hline GSSL (Resim) & 60 & 82,53 & 4951,5 & \multirow{2}{*}{2038,5} & \multirow[b]{2}{*}{.031} \\
\hline Kız Mes. Lis. & 86 & 67,2 & 5779,5 & & \\
\hline GSSL (Resim) & 60 & 76,32 & 4579 & \multirow[b]{2}{*}{1631} & \multirow{2}{*}{.011} \\
\hline İmam Hatip Lis. & 73 & 59,34 & 4332 & & \\
\hline GSSL (Resim) & 60 & 81,32 & 4879 & \multirow[b]{2}{*}{1871} & \multirow[b]{2}{*}{.015} \\
\hline Sağlık Mes. Lis. & 82 & 64,32 & 5274 & & \\
\hline GSSL (Res im) & 60 & 56,63 & 3397,5 & \multirow{2}{*}{832,5} & \multirow{2}{*}{.009} \\
\hline GSSL (Müzik) & 40 & 41,31 & 1652,5 & & \\
\hline Kız Mes. Lis. & 86 & 80,2 & 6897,5 & \multirow[b]{2}{*}{3156,5} & \multirow[b]{2}{*}{.004} \\
\hline Ticaret Lisesi & 97 & 102,46 & 9938,5 & & \\
\hline Kız Mes. Lis. & 86 & 73,81 & 6348 & & \\
\hline Turizm Mes. Lis. & 75 & 89,24 & 6693 & 2607 & .036 \\
\hline Kız Mes. Lis. & 86 & 51,79 & 4454 & 713 & 001 \\
\hline Spor Lisesi & 29 & 76,41 & 2216 & & .001 \\
\hline Tarım Mes. Lis. & 97 & 87,34 & 8472 & & \\
\hline Ticaret Lisesi & 97 & 107,66 & 10443 & 3719 & .011 \\
\hline Tarım Mes. Lis. & 97 & 58,36 & 5661 & & \\
\hline Spor Lisesi & 29 & 80,69 & 2340 & 908 & .004 \\
\hline Ticaret Lisesi & 97 & 95,32 & 9246 & & \\
\hline İmam Hat. Lisesi & 73 & 72,45 & 5289 & 2588 & .003 \\
\hline Ticaret Lisesi & 97 & 100,58 & 9756,5 & & \\
\hline Sağlık Mes. Lis. & 82 & 77,48 & 6353,5 & 2950,5 & .003 \\
\hline Ticaret Lisesi & 97 & 75,24 & 7298,5 & & \\
\hline GSSL (Müzik) & 40 & 53,86 & 2154,5 & 1334,5 & .004 \\
\hline Turizm Mes. Lis. & 75 & 82,49 & 6187 & & \\
\hline İmam Hat. Lisesi & 73 & 66,29 & 4839 & 2138 & .021 \\
\hline Turizm Mes. Lis. & 75 & 87,19 & 6539 & 2461 & 03 \\
\hline Sağlık Mes. Lis. & 82 & 71,51 & 5864 & 2401 & .03 \\
\hline Turizm Mes. Lis. & 75 & 63,63 & 4772 & & \\
\hline GSSL (Müzik) & 40 & 47,45 & 1898 & 1078 & .013 \\
\hline İmam Hat. Lisesi & 73 & 44,42 & 3242,5 & & 000 \\
\hline Spor Lisesi & 29 & 69,33 & 2010,5 & 541,5 & .000 \\
\hline İmam Hat. Lisesi & 73 & 72,08 & 5261,5 & & \\
\hline Öğretmen Lisesi & 86 & 86,73 & 7458,5 & 2560,5 & .045 \\
\hline Sağlık Mes. Lis. & 82 & 49,5 & 4059 & & \\
\hline Spor Lisesi & 29 & 74,38 & 2157 & 656 & .000 \\
\hline Spor Lisesi & 29 & 70,21 & 2036 & & \\
\hline Öğretmen Lisesi & 86 & 53,88 & 4634 & 893 & .022 \\
\hline Spor Lisesi & 29 & 45,34 & 1315 & & \\
\hline GSSL (Müzik) & 40 & 27,5 & 1100 & 280 & .000 \\
\hline Öğretmen Lisesi & 86 & 68,39 & 5881,5 & $1299 \quad 5$ & 027 \\
\hline GSSL (Müzik) & 40 & 52,99 & 2119,5 & 1299,5 & $.0<1$ \\
\hline
\end{tabular}


Tablo incelendiğinde anlamlı farkın hangi gruplar arasında olduğunu belirlemek amacıyla yapılan Mann Whitney U testi ikili karşılaştırmalarında tüm lise türleri arasındaki farkın anlamlı olduğu görülmüştür. Tabloda ikili karşılaştırmalar arasındaki bu anlamlı farkın hangi okulun lehine olduğu (U değeri ve sıra ortalamasına bakılarak) koyu karakterle belirtilmiştir.

\section{SONUÇ VE TARTIŞMA (CONCLUSION AND DISCUSSION)}

Araştırma bulgularına göre, okul türüne göre lise öğrencilerinin gelecek beklentisi toplam puanları arasında anlamlı fark olduğu görülmüşür. Sıra ortalamaları dikkate alındığında, en yüksek gelecek beklentisine sahip okul türünün spor Lisesi (535.22) olduğu, bunu sırasıyla Ticaret Lisesi (534.03), Tarım Lisesi (483,44), Imam Hatip Lisesi (477.23), GSSL (Resim Bölümü) (472.85), Endüstri Meslek Lisesi $(470,92)$, Anadolu Lisesi $(462,55)$, Sağlık Meslek Lisesi $(460,43)$, Tur. ve Otelcilik Lisesi $(455,77)$, Öğretmen Lisesi $(432,79)$, Kız Meslek Lisesi (402,49) ve GSSL(Müzik Böl.) (354,04)'nin izlediği görülmektedir.

Gelecek beklentisi alt boyutları puanları arasında da okul türüne göre fark olduğu bulgusuna ulaşılmıştır. İş ve Eğitim Beklentisi alt boyutunda, en yüksek sıra ortalamalarına sahip liselerin Ticaret (554,47), Anadolu (517,57), Tarım $(480,80)$ ve GSSL(Resim Bölümü) (473,15); en düşük sıra ortalamalarına Kız Meslek $(399,99)$ ve GSSL(Müzik Bölümü) $(403,85)$ 'nin;

Evlilik ve Aile Beklentisi alt boyutunda, en yüksek sıra ortalamalarına sahip liselerin Spor $(608,60)$, Ticaret $(516,62)$, İmam Hatip $(505,09)$ ve Endüstri Mes. $(492,28)$ Liselerinin; en düşük sıra ortalamalarına GSSL(Müzik Bölümü) (337,88), Öğretmen Lisesi $(410,36)$ ve Kız Meslek $(417,98)$ liselerinin,

Din ve Toplum Beklentisi alt boyutunda, en yüksek sira ortalamalarına sahip liselerin Imam Hatip $(602,03)$, fpor $(570,43)$ ve Endüstri Mes. Liselerinin (524,04), en düşük sıra ortalamalarına GSSL(Müzik Bölümü) $(327,53)$, Anadolu $(369,73)$ ve GSSL(Resim Bölümü) $(427,99)$ 'nin,

Sağlık ve Yaşam alt boyutunda ise, en yüksek sıra ortalamalarına sahip Liselerin Spor $(609,60)$ Ticaret $(541,59)$ GSSL(Resim Bölümü) $(512,92)$ 'nin; en düşük sıra ortalamalarına GSSL(Müzik Bölümü) (381,91), İmam Hatip $(411,49)$ ve Sağlık $(420,60)$ liselerinin sahip olduğu görülmektedir.

Gelecek beklentisi toplam puanı ve alt boyutlara ait puan farklarına bakıldığında da sıra ortalamaları yüksek liselerin lehine anlamlı farklılık olduğugörülmektedir. Şimşek (2011) yaptığı çalışmada öğrencilerin beklenti düzeylerinin Kişisel-Mesleki, Eğitsel, Ekonomik, Sosyal ve gelecek alt boyutlarında ortanın üstünde olduğu görülmüştür. Eryılmaz (2011), ergenlerin geleceğe yönelik olumlu beklentileri ile öznel iyi oluş düzeyleri arasında ilişkiyi araştırdığı çalışmasında, geleceğe yönelik olumlu beklentilere sahip olan ergenlerin öznel iyi oluş düzeylerinin de anlamlı ve önemli düzeyde yükseldiği sonucuna varmıştır. Literatürdeki bulgular da aynı doğrultudadır. Eryılmaz ve öznel iyi oluş ile ilgili literatürün sonuçları bağlamında bakıldığında, özellikle gelecek beklentisi toplam puanlarında ve alt boyut puanlarında genellikle düşük puanlara sahip olduğu görülen GSSL(Müzik Bölümü), Kız Meslek, Öğretmen Liselerinin gelecekle ilgili beklenti düzeylerinin düşüklüğünü araştıracak nitel çalışmalar yapılmalıdır. Bu yönüyle öğrencilerin gelecek beklentileriyle ilgili algılarını ve bu algıların ne yönde olduğunu derinlemesine sorgulayabilecek odak grup görüşmesi gibi nitel çalışmaların konuyu derinlemesine inceleme noktasında yardımcı olacağı düşünülmektedir. 
Ayrıca bu okul türlerine devam eden öğrenciler, olasılıkla Ticaret Lisesi öğrencileri kadar özellikle iş ve eğitim alt boyutunda şanslı olmadıklarını düşünüyor olabilirler. Bu sonuçlardan manidar olanı Öğretmen Liselerinin gelecek beklentileri toplam puanı sıra ortalamalarında listenin aşă̆ılarında yer almasıdır. Sayısal ve sözel derslerinin diğer okul türlerine göre en iyi seviyede oldukları bilinen Öğretmen Liselerinin aşağı sıralarda yer alması düşündürücüdür. Başkonuş ve ark. 2011 yılında Eğitim Fakültesinin farklı bölümlerinde son sınıf öğrencilerinin gelecek beklentilerini araştırdıkları bir çalışmada Eğitim Fakültesi öğrencilerinin (71/19) -26'sının atanacağından umutlu olduğu görülmüştür. Bunun yanında öğretmenlik mesleğinin düzenli bir aile ortamı sağlayacă̆ına ilişkin görüşler o76'yı bulmaktadır. Dolayısıyla üniversite öğrencilerinin beklentilerinin olumlu olması, belli bir lise türünü seçmekte olan ve seçmiş olan öğrencilerin beklentilerinde önemli rol oynamaktadır. Tuncer(2011) tarafındanyapılan araştırmada meslek lisesinden gelen öğrencilerin gelecek beklentisi puanları ile diğer liselerden gelen öğrencilerin puanları arasında anlamlı bir fark bulunamamıştır. Tuncer (2011) ayrıca sınavsız geçiş, meslek standartlarının oluşturulması ve akreditasyon, iş yaşamına yönelik değişimler gibi çeşitli unsurların Meslek Yüksekokulu öğrencilerinin gelecek beklentilerini etkileme gücüne sahip olduğunu ifade etmiştir.

Yavuzer ve ark. (2005) göre ise, lise ve üniversite öğrencilerinin gelecek beklentilerinin meslek, evlilik, ekonomik kazanç ve toplumsal saygınlık hedeflerinde benzer şekilde yoğunlaştığı bulgulanmıştır. Benzer beklentilerin yanı sıra araştırmada, lise öğrencilerinin karşı cinsle yakın ve özel ilişkiler geliştirmek ve aileden bağımsız bir yaşam kuruponu sürdürebilmeyi hedeflerken, üniversite öğrencilerinin daha çok yaşam felsefesi geliştirmeyi hedefledikleri ifade edilmiştir.

Evlilik ve aile alt boyutunda Spor, Ticaret, İmam Hatip ve Endüstri Meslek Lisesi puanlarının diğer lise türlerine göre yüksek çıkması, bu okul türlerinde öğrenim gören öğrencilerin gelecekte iş ile ilgili kaygılarının daha az olabileceği anlamına gelebilir. Özellikle Ticaret Lisesi öğrencilerinin iş ve eğitim alt boyutunda puan olarak diğer öğrencilerden anlamlı derecede yüksek olduğu araştırma sonuçları arasındadır. Güleri (1994) tarafından, çalışan gençliğin üniversite öğrencisinden daha geniş bir oranda o34 iyi bir eş beklentisinin olduğu, bu sonucunda bu gençlerin zaten çalıştıkları bir işin mevcut olmasıyla açıklanabileceği vurgulanmıştır. Bayoğlu ve Purutçuoğlu (2011) tarafından yapılan yetiştirme yurdunda kalan ergenlerin gelecek beklentilerinin ve sosyal destek algılarının araştırıldığı bir araştırmada da ergenlerin beklentilerinin en çok eğitim, iş ve ekonomik konulara ilişkin olduğu, bunu aile yaşamı ve sağlık ile ilgili gelecek beklentilerinin izlediği görülmüştür.
Araştırmanın
sonuçları
ve diğer
araştırmalar

karşılaştırıldığında lise öğrencilerinin beklentilerinin, öncelikle beklentilerinin iş ve eğitim alanlarında olduğu, spor Lisesinin sağlık ve yaşam alanlarında, İmam Hatip Lisesinin din ve toplum alanlarındaki beklentilerinin yüksek olmasının aldıkları eğitimin türünden kaynaklanan özel bir durum olduğu söylenebilir. Araştırmanın amaçları arasında yer alan Güzel Sanatlar ve spor Liselerinin diğer lise türleri ile gelecek beklentisi farklarının araştırılmasına bağlı olarak, Güzel Sanatlar Lisesi Resim Bölümünün gelecek beklentisi açısından diğer liselerle arasında anlamlı bir fark olmadığı görülmüştür. Ayrıca, Güzel Sanatlar Lisesi Resim Bölümünün Müzik Bölümü ile gelecek beklentisi arasında Resim Bölümü lehine anlamlı bir fark olduğu, Güzel Sanatlar Lisesi Müzik Bölümü öğrencilerinin gelecek beklentileri toplam puanında ve beklenti ölçeklerinin alt boyutları 
Uluçay, T., Özpolat, A.R., İşör, $\dot{I} . Y$. ve Taşkesen, 0 . NWSA-Education Sciences, 1C0616, 9, (2), 234-247.

puanlarında diğer lise türleri lehine anlamlı bir fark olduğu
görülmüsür.
Sonuç olarak, Güzel Sanatlar Lisesi Müzik Bölümü öğrencilerinin
gelecekten beklenti düzeyi puanlarındaki düşülüğü derinlemesine
araştırılması gerekir. Zira gelecek beklentisinin düsük olmasının
öznel iyi oluşu olumsuz etkilediği (Eryılmaz, 2011), umutsuzluk
düzeyini artırdığı (Dilbaz ve Seber, 199, Çokluk, 2000)
bilinmektedir. Ayrıca, ergenlerin gelecekteki beklentilerinin onların
gelecekle ilgili korkularını ortaya koyduğu geleceğe ilişkin olumlu
inançların, uzun dönemli planların daha iyi bir eğitime ve işe sahip
olunacağına ilişkin inanç, okulda daha iyi bir sosyal ve duygusal uyum
ile birbirine bağlı olduğu bilinmektedir (Bayoğlu ve Purutçuğlu). Bu
bulgular lşığında Güzel Sanatlar ve Müzik Bölümü öğrencilerinin
gelecek beklentilerinin olumlu yönde değiştirilmesi bu öğrencilerin
görece kişisel ilişkilerini ve kendilik alglarını da olumlu yönde
etkileyecektir.

\section{KAYNAKLAR (REFERENCES)}

1. Başkonuş, T., Akdal, D. ve Taşdemir, M., (2011). Ahi Evran Üniversitesi Eğitim Fakültesi Son Sınıf Öğrencilerinin Gelecek Beklentileri, 2nd International Conference on New Trend in Education and Their Implications, 27-29 April, 2011 Antalya

2. Bayoğlu, A.S. ve Purutçuoğlu, E., (2011). Yetiştirme yurdunda kalan ergenlerin gelecek beklentileri ve sosyal destek algıları, Kriz Dergisi, $18(1): 27-39$

3. Beal S.J. and Crockett, L.J., (2010). Adolescents' Occupational and Educational Aspiration sand Expectations: Links to High School Activities and Adult Educational Attainment, Developmental Psychology, 46(1):258-265 DOI:10.1037/a0017416

4. Chardie, L. Baird, S.W., and Burge, J.R.R., (2008). Absurdly Ambitious? Teenagers' Expectations for the Future and the Realities of Social Structure, Sociology Compass2(3): 944-962

5. Çokluk, Ö., (2000). Örgütlerde Tükenmişlik: Yönetimde Çağdaş Yaklaşımlar. (Edit: Cevat Elma ve Kamile Demir). Ankara: Anı Yayıncılık.

6. Dilbaz, N. ve Seber, G., (1993). Umutsuzluk Kavramı: Depresyon ve İntiharda Önemi. Kriz Dergisi, 1(3): 134-138.

7. Eryılmaz, A., (2011). Ergen Öznel İyi Oluşu ile Olumlu Gelecek Beklentisi Arasındaki İlişkinin Íncelenmesi, Düşünen Adam Psikiyatri ve Nörolojik Bilimler Dergisi, 24(3):209-215. DOI: $10.5350 /$ DAJPN2011240306

8. Heubner E.S., (1991). Correlates of life satisfaction in children. School PsychologyQuarterly6:103-111.

9. TDK, (2011). Türk Dil Kurumu Sözlüğü. http://www.tdk.gov.tr

10. Eccles, J. and Barber, B., (1999). Student council, volunteering, basketball, or marchingband: Whatkind of extra curricular involvemen tmatters? Journal of Adolescent Research, $14(1): 10-43$.

11. Erikson, E.H., (1968). Identity: Youthandcrisis. New York, NY: Norton

12. Fıschhoff, B., Parker, A.M.Br., Downs, J., Palmgren, C., Dawes, R., and Manski, C.F., (2000). Teen Expectatıons for Significant Life Events, Public Opinion Quarterly Volume 64: 189-205

13. Guarino, A., De Pascalis, V., and DiChiacchio, C., (1999). Breast can cerprevention, time perspective, and trait anxiety. Unpublished Manuscript, University of Rome

14. Güleri, M., (1994., Üniversiteli ve İş̧̧i Gençlerin Gelecek Beklentileri ve Kötümserlik- Iyimserlik Düzeyleri, Kriz Dergisi 6 (1) : 55-65 
15. Kazakina, E., (1999). Time perspective of older adults: relationships to attachment style, psychological well-being and psychological distress. Unpublished Doctoral Dissertation, Columbia University.

16. McCabe, K. and Barnett, D., (2000). First comes work, then comes marriage: Future orientation among African American young adolescents. Family Relations, $49(1)$ : 63-70.

17. Mello, Z.R., (2008). Gender Variation in Developmental Trajectories of Educational and Occupational Expectations and Attainment from Adolescencet Adulthood, Development Psychology, 44 (4): 1069-1080. DOI:10.1037/0012-1649.44.4.1069

18. Raffaelli, M. and Koller, S.H., (2005). Future expectations of Brasilian street youth. Journal of Adolescence, 28(2): 249-262.

19. Sipsma H.L., Ickovics J.R., Lin H., and Kershaw, T.S., (2012). Future Expectations Among Adolescents: Alatent Class Analysis, Am J Community Psychol, September; $50(1-2)$ : 169181.DOI:10.1007/s 10464-011-9487-1

20. Şimşek, H., (2011). Güneydoğu Anadolu Bölgesindeki Lise Öğrencilerinin Gelecek Beklentileri ve Gelecek Beklentilerini Etkileyen Faktörler, Kuramsal Eğitim Bilimleri Dergisi- Journal of Theoretical Educational Science, 5(1):90-109.

21. Tokuç, B., Evren, H. ve Ekuklu, G., (2009). Edirne ve Hayranbolu Mesleki Eğitim Merkezi Öğrencilerinde umutsuzluk ve Sürekli Kaygi Düzeyleri. TAF PrevMedBull; 8 (2): 155-60.

22. Tuncer, M., (2011). Ergen Gelecek Beklentileri Ölçeğinin Türkçeye Uyarlanması Turkish Studies- International Periodical for the Languages, Literature and History of Turkish or Turkic Volume 6(3):1265-1275 TURKEY

23. Tuncer, M., (2011). Yükseköğretim Gençliğinin Gelecek Beklentileri Üzerine Bir Araştırma, Turkish StudiesInternational Periodical for the Languages, Literature and History of Turkish or Turkic, 6(2):935-948 TURKEY.

24. Turcios-Cotto, V. and Milan, S., (2013). Racial/ Ethnic Differences in the Educational Expectations of Adolescents: Does Pursulng Higher Education Mean Some thing Different to Latino Students Comparedto White and Black Students?, Journal of Youth \& Adolescence; Sep 2013,42 (9): 1399-1412, DOI:10.1007/s 10964012-9845-9.

25. Yavuzer, H., Demir, İ., Meşeci, F. ve Sertelin, Ç., (2005). Günümüz Gençliğinin Gelecek Beklentileri, Hasan Ali Yücel Eğitim Fakültesi Dergisi 2:93-103. 